NBER WORKING PAPER SERIES

\title{
THE MACRO-FOUNDATIONS OF MICROECONOMICS: INITIAL LABOR MARKET CONDITIONS AND LONG-TERM OUTCOMES FOR ECONOMISTS
}

\author{
Paul Oyer \\ Working Paper 12157 \\ http://www.nber.org/papers/w12157 \\ NATIONAL BUREAU OF ECONOMIC RESEARCH
1050 Massachusetts Avenue
Cambridge, MA 02138
April 2006
}

I am trying to make the dataset used in this paper as complete and accurate as possible. It includes people that got PhDs in economics from Berkeley, Northwestern, Stanford, MIT, and the Universities of Chicago, Texas, and Minnesota and went on the job market between 1979 and 2004. I would be grateful to anyone in this group (whose CV is not easily available online) who sends me a current $\mathrm{CV}$ or resume at the contact information below. I thank Robert Gibbons, James Hines, Uri Simonsohn, Timothy Taylor, Michael Waldman, and seminar participants for comments. I am very grateful to the placement directors and graduate program administrators who provided historical economics job market materials. James Caputo, Eric Forister, Michael Grubb, Diane Lee, and Khine Williams provided excellent research assistance. I also want to thank Bill Clinton, Alan Greenspan, and anyone else responsible for the fact that the economy was healthy during the 1995-1996 academic year. Author contact: Stanford University Graduate School of Business and NBER, 518 Memorial Way, Stanford, CA 94305-5015. e-mail: pauloyer@ stanford.edu. Phone: (650) 736-1047. The views expressed herein are those of the author(s) and do not necessarily reflect the views of the National Bureau of Economic Research.

(C2006 by Paul Oyer. All rights reserved. Short sections of text, not to exceed two paragraphs, may be quoted without explicit permission provided that full credit, including $(\odot)$ notice, is given to the source. 
The Macro-Foundations of Microeconomics: Initial Labor Market Conditions and Long-Term Outcomes for Economists

Paul Oyer

NBER Working Paper No. 12157

April 2006

JEL No. J24, J44, A11, M50

\begin{abstract}
$\underline{\text { ABSTRACT }}$
Each year, graduate students entering the academic job market worry that they will suffer due to uncontrollable macroeconomic risk. Given the importance of general human capital and the relative ease of publicly observing productivity in academia, one might expect unlucky graduating cohorts' long-term labor market outcomes to resemble those who graduate in favorable climates. In this paper, I analyze the relationship between macroeconomic conditions at graduation, initial job placement, and long-term outcomes for $\mathrm{PhD}$ economists from seven programs. Using macro conditions as an instrument for initial placement, I show a causal effect of quality and type of initial job on long-term job characteristics. I also show that better initial placement increases research productivity, which helps to limit the set of economic models that can explain the effect of initial placement on long-term jobs.
\end{abstract}

\author{
Paul Oyer \\ Graduate School of Business \\ Stanford University \\ 518 Memorial Way \\ Stanford, CA 94305-5015 \\ and NBER \\ pauloyer@stanford.edu
}




\section{Introduction}

There is much speculation each year among graduate students who are leaving school about whether they will face a "good" job market. Given the years of work, minimal compensation, and, in some cases, large investments in tuition, it is only natural for graduates to hope to reap the benefits of their educational investments. Conventional wisdom and casual empiricism suggests that the state of the job market is important in determining pay and initial job placement immediately after leaving graduate school. But several economic theories suggest that these short-term effects of macroeconomic conditions can persist so that graduating in a "good" year provides an element of randomness that can have a long-term influence on pay and the types of work people do.

In this paper, I study a set of high-skill graduates whose careers can be affected by initial macroeconomic conditions - PhD economists. There have been numerous studies of how macroeconomic conditions affect large samples of people across a large set of occupations. Two potential issues with these studies are that many employees transition slowly into the labor force, making it difficult to isolate a single "entry" point, and that the average effects in these large samples may mask interesting differences across professions. The innovation in this paper is to focus on a set of professional graduates where the date of final entry into the labor market is easily identifiable and can plausibly be considered exogenous. While economists are not representative of the economy as a whole, they provide a useful portrait of the increasingly important high-skilled "knowledge" workers.

By using macroeconomic conditions at the time of graduation to instrument for the first job held by a new economist, I can estimate the causal effect of the first job on longer-term outcomes. Note, however, that I do not have compensation data, so the labor market outcomes I study are type of job and proxies for job quality. The results, therefore, have only indirect implications for long-term wealth, but directly address issues of human capital development.

I show that first jobs matter a great deal for PhD economists. Those who graduate when demand for economists is high are far more likely to obtain a tenure-track position at a ranked institution and, more specifically, are more likely to get a job at a top 50 university. Transition in and out of attractive positions is very small, so those who start with "good" jobs are much more likely to hold them later in their careers. By using instruments for initial demand for economists, I argue that there is a causal link between the quality of an economist's first job and the quality of his position anywhere from three to fifteen years later. As I discuss in the next section, several economic theories would predict this relationship between initial and long-term outcomes. While I cannot fully isolate the source of the cohort effects for economists, I can use publication records to look at productivity differences among those who get good first jobs through the "luck" of a 
good market and those who have bad luck initially. I find that getting a "good" first job increases publication productivity, which suggests that models of "influence activity" and simple inertia do not drive the results.

Perhaps the "experiment" and results are best understood through the following hypothetical example. Consider an economist who receives his $\mathrm{PhD}$ during a favorable economic period when university budgets create many open positions. Suppose this person accepts a position as an assistant professor at Boston University (ranked as the thirtieth best economics department in the world by Coupe (2003), twenty-second by Kalaitzidakis, Mamuneas and Stengos (2003), and twenty-sixth by "econphd.net.") He goes on to have a career at BU and possibly other institutions including universities, government agencies, and the private sector. Now suppose the same person was born a few years earlier or later and he receives his $\mathrm{PhD}$ during a "buyer's market" when school budgets are tight. Due to the lower demand for economists, he ends up taking a position at Washington University in Saint Louis (ranked forty-eighth, fifty-third, and sixty-third, respectively, by the same authors.) The change to graduating in a less favorable climate has clearly hurt this person's career initially. But, some number of years after taking his first position, is he any worse off if he starts at Washington University than if he starts at BU? Or does the market adjust his position over the years so that, regardless of where he starts, he ends up matched to an appropriate institution given his skills and preferences? I show that he is much more likely to end up at an institution of the caliber of $\mathrm{BU}$ if he starts at BU than if he starts at Washington University. I also ask whether these longer-term advantages are due to the fact that his initial luck leads him to be more productive in the initial phase of his career than he would have been had he placed at a lower-ranked school. That is, do the advantages that might come with working at a higher ranked school (including lighter teaching loads, higher visibility in the profession, and more accomplished colleagues) make people more productive and, therefore, more successful over their careers? While I cannot isolate which potential advantage of working at BU makes him more productive, I show that he is more likely to end up at a higher-ranked job because his initial placement at BU makes him more productive than he would have been at Washington University.

Given the measures of labor market outcomes available, I will not analyze wages. As a result, this paper differs significantly from prior work on cohort effects. In these papers, job quality is typically defined by wages. A recent example, which is similar in many ways to the exercise I perform, is Oreopoulos, von Wachter and Heisz (2005). They look at the early careers of Canadian college graduates. They find that graduating in a recession has little effect on employment, but adversely affects early career income. They go on to show that these effects fade over the first decade of a career. Most of their results are due to people accepting jobs at small, low-paying firms 
during recessions and moving to higher-pay firms (where the pay differences can be attributed to size or industry) when the economy recovers. Kahn (2005) uses the National Longitudinal Survey of Youth to study U.S. college graduates in the classes of 1979-1988. She finds that macroeconomic conditions have important wage effects (which are more persistent than those found by Oreopoulos et al. (2005)) and that this is largely due to the occupations where graduates start. She finds no effect on labor supply, except that those who graduate during a recession are more likely to go to graduate school. Oyer (2006) shows that macroeconomic conditions at graduation affect the type of firms that employ new MBAs and that this leads to significant long-term effects on labor income.

The conclusion that cohort effects on pay are due to sorting among firms rather than within-firm cohort effects is consistent with Beaudry and DiNardo (1991). They show that macroeconomic conditions at the time an employee starts a job are not an important determinant of wages, controlling for the best conditions during the employee's tenure. However, Devereaux (2004) and Baker, Gibbs and Holmstrom (1994) show that the timing of the start of a job can have long-term wage effects. Devereaux (2004) shows that, relative to "comparable" people, workers who accept low-paying jobs are stuck with low wages for at least several years. Some, but not all, of this effect goes away for those who switch jobs. Baker et al. (1994) document cohort effects on wages within a single firm.

A large set of papers has studied economists. Many of these, including Coupe (2003) and Kalaitzidakis et al. (2003), simply rank the research output of individuals or their institutions. ${ }^{1}$ I use these rankings to generate various measures of the quality of economists' jobs. A smaller set of papers, including Coupe, Smeets and Warzynski (2006) and Smeets (2004), have studied the labor market for economists and found that the economics labor market provides incentives through potential promotion and mobility. ${ }^{2}$ Swidler and Goldreyer (1998), Siow (1991), and Hamermesh, Johnson and Weisbrod (1982) document that there are strong financial incentives to generate research. The availability of "performance" (that is, publication) information makes the economist labor market attractive to study. ${ }^{3}$ However, the lack of salary information introduces a limitation

\footnotetext{
${ }^{1}$ See Neary, Mirrlees and Tirole (2003) for a discussion of the relative advantages of these and other rankings of economists and institutions.

${ }^{2}$ For basic information about the market, see Siegfried and Stock (1999) and Siegfried and Stock (2004). For a historical perspective on the market for economists, see Brook and Marshall (1974). They discuss the matching process, describe the state of supply and demand as of 1974, and recommend starting a publication that became Job Openings for Economists. Also, see Tervio (2005b) for a study of networks within the economics labor market and a comparison with other academic labor markets. Goyal, van der Leij and Gonzalez (2006) study economist co-authoring networks. There is a large literature studying academic labor markets more broadly. See Ehrenberg (2003) for an overview of recent work and references to past studies.

${ }^{3}$ Einav and Yariv (2006) also use productivity measures and study the effect of another source of luck - alphabetic placement of economists' surnames - on economist careers. They show that economists with last names starting further down in the alphabet face a handicap because they are more likely to be listed later on papers' author lists.
} 
in interpreting labor market outcomes. Also, because local labor markets for economists are fairly illiquid, often requiring people to move when changing jobs, this market may not be typical of other high-skill labor markets and the results may not generalize to labor markets more broadly.

The rest of the paper proceeds as follows. Drawing on other work, the next section lays out the theoretical background for why initial placement might have long-term implications. Section 3 provides details on the dataset of economist careers and productivity. Section 4 documents the effect of macroeconomic conditions on economists' initial job placement. Section 5 shows that initial placement affects long-term placement and research productivity. Section 6 concludes with a summary and suggestions for future research.

\section{Theoretical Background}

There are several economic theories that would suggest "stickiness" (or "cohort effects") in first jobs after graduation. That is, there are many possible reasons to think that the type and quality of a person's initial job will have a long-term effect on the type and quality of jobs they hold for years after starting their careers. Therefore, finding a long-term effect of initial placement will not distinguish among these models. However, using economist publication records as a measure of productivity, I can also analyze whether first placement affects productivity. So, in the following discussion of long-term effects of first placement, I consider each model's implication for the effect of first job on productivity.

Firm-specific human capital may influence the value of on-the-job investments of workers, making them more valuable at their initial employers than elsewhere. The value provided by economists is typically thought to be due to general human capital. But if organizations differ in, for example, their mix of research and teaching or if people become attached to their co-workers, then the models in Lazear (2003) and Hayes, Oyer and Schaefer (2006) can generate similar implications to classical versions of firm-specific human capital. Under these models, I would expect that getting a good first job will have a positive effect on economist research productivity due to the orientation towards research and the spillovers from more successful colleagues at top institutions. ${ }^{4}$

A related idea, with a more direct tie to the empirical analysis here, can be found in the model developed by Gibbons and Waldman (2006) and related discussion in Gibbons and Waldman (2004).

For studies of research productivity over the life cycle in economics and the natural sciences, see Weinberg and Galenson (2005) and Levin and Stephan (1991).

\footnotetext{
${ }^{4}$ While it would obviously come as no surprise to find that economists at higher ranked schools have higher research output, the predictions here and the empirical analysis below are about the causal effect of a given economist (that is, conditional on "ability") obtaining an initial placement at a higher ranked institution.
} 
They suggest that initial conditions can be important in long-term labor market outcomes because of the effect on on-the-job skill development. In their model, employees develop "task-specific human capital." Those hired under more favorable conditions are initially given higher value tasks and develop more valuable human capital that persists throughout their careers. In terms of productivity, the initial investments in research skills would lead economists who place at better institutions to be more productive (again, in the causal sense.)

Suppose people's tastes evolve based on their experience and environment (see Frank (1984) and Rayo and Becker (2005)). Then people who place into top institutions may get caught up in the local norm of what is considered success, with a heavy emphasis on research. Conversely, those who do not place as well may place greater focus on less research-oriented activities, including teaching, community service, or their personal lives. This leads economists that initially work at top institutions, even if they place there only due to job market timing, to be more likely to stay at a top institution and to be more productive than initially unlucky economists.

Another class of models regarding co-workers focuses on "influence activity" (see, for example, Milgrom (1988).) This idea would suggest that people get ahead (get tenure) based on their ability to influence their colleagues. Those who place well initially have better long-term outcomes due to their ability to influence people at better institutions. However, people would not necessarily be any more productive as a result of getting a better job. ${ }^{5}$

An alternative idea, with similar empirical implications, is that the job market takes initial job placement as a signal of ability and fails to compensate for the "luck" associated with initial market conditions. For this idea to apply to the economist job market would imply non-rational behavior among a group that prides itself on rationality. However, given that Einav and Yariv (2006) suggest that economists do not properly compensate for the first letter of each others' last names in evaluating one another, it seems plausible that they would also fail to fully account for labor market conditions on first jobs. ${ }^{6}$

Models where search is costly (either for firms or employees) also leads to frictions where initial jobs are likely to become long-term. Models where incumbent firms have useful private information (such as Akerlof (1970) and Waldman (1984)) about employee productivity have similar implications. Again, pure forms of these models do not suggest that initial placement will affect

\footnotetext{
${ }^{5}$ There may, however, be cases where influence activity can lead to the appearance of increased productivity. For example, the senior economist could be a journal editor and accept her colleague's papers or she could give her junior colleague too much credit when they write papers together. I will not be able to separate this form of influence activity from "productive" activity.

${ }^{6}$ Siow (1991) develops a model where employers of academics rely heavily on early publications, which may affect early placement. This model also does not suggest initial placement will affect productivity.
} 
productivity.

A recent and intriguing model that could apply to the economist market is Tervio (2005a), who considers a case where skill is industry-specific and learned on-the-job and where productivity is publicly observable. Workers stay at the same type of firm (though not necessarily the same firm) even though social welfare would be improved if experienced workers were more regularly replaced by fresh graduates. Individual firms do not have an incentive to do this, however, because a new employee that turns out to be a star can simply leave. This model would not predict that getting a good job will increase productivity.

\section{A New Dataset of Economists}

I constructed a new dataset of economist careers. Though the data itself is consistent and accurate, the basis of the sample was somewhat random. I began by contacting economics department chairpeople, faculty in charge of graduate placement, and administrators of graduate programs. I either relied on my own personal contacts, the recommendations of colleagues, or I simply sent "cold-call" e-mails to the relevant people. As far as I know, it is a universal practice among top economics departments to create a book each Fall that contains the CVs of all graduate students who, at the time the books are generated, expect to be on the job market that academic year. I asked for copies of these books going back as far as I could get. Responses to this request fell into one of three categories. First, a few schools simply ignored my request. Second, several schools were very helpful but they did not keep copies of the old books of CVs for enough years to make it worth pursuing. Third, seven schools had copies of the books going back to at least the late 1980s and they sent me copies of each book from as early as they had through the Fall of 2003. While there could be selection effects in the set of schools that provided CVs, I see no reason why schools that made $\mathrm{CV}$ books available would be different in any systematic way from schools that did not have this information. My impression from this data-gathering exercise is that the dominant factor in a school making the $\mathrm{CV}$ books available to me was the existence of a graduate program administrator who was both very organized and had been in the position for a long period.

The seven schools from which I have CV books are the University of California at Berkeley, the University of Chicago, the University of Minnesota, the Massachusetts Institute of Technology, Northwestern University, Stanford University, and the University of Texas. Five of the seven have been consistently ranked among the ten best in the world over the entire period I study. At least two of these departments could and have made legitimate cases that they are the very best department in the world at various points over this period. Minnesota and Texas are generally ranked anywhere 
from tenth to thirtieth in the world, depending on survey methodology. ${ }^{7}$

For each CV in each book at the seven schools, I first created a dataset of information from the CVs themselves. I entered full names as they appeared on the CV, the research fields of the person (or, if they did not list research areas, I used teaching fields or the fields in which the person passed examinations), up to two primary advisors, undergraduate institution, year undergraduate degree was received, and undergraduate major. I was able to assign gender to over $98 \%$ of the sample. For the vast majority of the sample, I inferred gender from people's names. When the name did not make gender obvious, I tried to find a picture online and used lists of names available in "Baby Name" books and internet sites. For three of the seven schools, the graduate program administrator was able to confirm gender for those I could not otherwise figure out. For almost all people, I created indicator variables for whether the person received National Science Foundation Graduate and Sloan Foundation Dissertation Fellowships. ${ }^{8}$

I then attempted to track the person's career year-by-year from the Fall of the year after the person's CV was in his graduate institution's CV book through 2004. I relied on several sources for this. Where possible, I used a current CV (which I typically found through an internet search) or biography on a web page. ${ }^{9}$ The second choice source was the $1981,1985,1989,1993,1997$, 2003, and current online directories of members published by the American Economics Association (AEA). The 1981-1997 directories were published as part of special December issues of the American Economic Review while the 2003 directory was made available online as a PDF document. Many AEA members provide significant biographical detail in these directories, while others provide no information or only current job as of the time of the survey. The third source was initial job placement reports provided by three of the seven schools and a current alumni directory provided by two schools. Naturally, the placement reports were only useful for identifying the first position the person held. The fourth source was the affiliations listed for authors in the EconLit database. The reason this source is not as good as the others is that EconLit does not typically indicate if the person holds a visiting position. Also, EconLit does not typically identify whether a person works

\footnotetext{
${ }^{7}$ I will not identify any person or school by name for the rest of the paper. However, I would like to appeal to readers who were $\mathrm{PhD}$ students at one of these schools and went on the job market between 1979 and 2004 to please send me your current CV or resume (see cover for my contact information) so that I can minimize measurement error. Any reader whose CV or a detailed bio is readily available through a Google search need not send me their information.

${ }^{8}$ For a few years in the early 1980's, one school only provided a summary table with names, advisors, fields, and educational background. Because I did not have complete CVs with details on honors and awards, I could not determine if these people had received NSF or Sloan fellowships.

${ }^{9}$ As an example of the distinction, the Board of Governors of the Federal Reserve posts biographies of their research economists that detail the positions the people have held since receiving PhDs. The site does not provide full CVs.
} 
at a professional school rather than in an economics department. The final source was indirect information found through internet search. Examples of this varied. Two common forms of useful indirect information were articles quoting economists ("Economist John Doe of Morgan Stanley predicted the peso would be stable...") and acknowledgements in articles ("We thank Jane Doe of the World Bank for the data..."). However, there were other random helpful sources, such as a graduate of one of the programs who posted a list of classmates he had found and their current jobs. $^{10}$

After assigning a job to a person for each year possible, I categorized these jobs along several dimensions. For people working at universities, I created an indicator variable for tenure-track positions (visitors, post-docs, research fellows, etc.)

In addition to these descriptions of the job, I categorized and ranked the institutions where people worked. Using these rankings and the job information, I created five measures of the quality of a given job. The first two measures are based on the 2004 rankings of economics research institutions available at www.econphd.net as of June 1, 2005. Universities are ranked from 1 to 321 and other organizations from 1 to 112. Details of the ranking system are available on the website. Based on looking at the econphd measure of "equivalent papers", which takes into account the number and length of articles published, it is clear that a university of a given rank is more productive than another organization of similar rank. I define "rank" as the rank between 1 and 321 for universities, fifty plus twice the rank from 1 to 112 for other organizations, and 350 for any organization that is not ranked at all. As examples of how schools compare to other institutions, this makes the ranking of the top non-university organization (the World Bank) equal to the ranking for Rutgers University and ranks the Bureau of Labor Statistics on a par with Pompeu Fabra.

I define "tenure-track ranked" jobs (which I will often refer to as "TTR" positions) as any tenure-track position at a university or college that is on econphd.net rankings. Finally, "Top 50" jobs are tenure track positions at schools in the top 50 of the econphd.net university rankings. Qualitative conclusions are not sensitive to substituting the university rankings in Coupe (2003) or Kalaitzidakis et al. (2003) for econphd.net rankings when defining these variables.

If I knew that a person held one job in year $t$ and another job in year $t+x$, I assumed that the person held the year $t$ job in years $t+1, t+2, \ldots, t+x-1$. If I was not able to determine what job a person held in a given year, I assumed that the person held a job that was not ranked by econphd.net. The one exception to this was the way I assigned initial positions. If I first found the person working at a job $t$ years after his last time on the job market, I assumed that he held

\footnotetext{
${ }^{10}$ In a particularly unusual example, I found one economist through a newspaper article about the mess left behind by wild turkeys in the Boston suburbs.
} 
that position from the year after going on the market until I found him at that job. Treating these observations the same as other missing observations has no material effect on any of the results.

I use four primary measures of the state of the macroeconomy. When looking at students looking for jobs starting in the Summer of year $t$, I use the level of the S\&P 500 as of the end of October of year $t-1$ and the unemployment rate for the U.S. as of October of year $t-1$. For more economist-specific measures of labor demand, I use the total number of jobs and the total number of academic jobs listed in the Job Openings for Economists (JOE) in year $t-1$. This information is published annually in the JOE director's report in the May "Papers and Proceedings" issue of the American Economic Review. Some of these jobs can be listed early in the year, at the tail end of the previous academic job market. However, the vast majority of listings in $J O E$ are in the Fall for openings in the following year.

Table 1 provides summary statistics of the sample as a whole, as well as for each of three of the graduate programs. To maintain confidentiality of individuals and institutions, I refer to these three graduate programs as "School A", "School B", and "School C." The sample is predominantly male and most people are American (using whether the person went to a U.S. undergraduate institution as a proxy.) Recently, the sample has become increasingly foreign but not more female. Of those entering the job market in the last five years of the sample, $22 \%$ were female and $49 \%$ went to American undergraduate institutions. In all analysis that follows, I group men and women together. In unreported analysis, I found no evidence that any of the results below vary systematically by gender.

Fewer than half of the sample gets placed initially, or holds at any given time, a tenure-track job at a ranked institution and about a quarter of the sample holds a position at a top 50 university. These measures of job quality, as well as pre-graduation indications from high-profile fellowships, vary greatly between which graduate program the person attended. Publication success also varies significantly between schools, with those who graduate from "School C" publishing at about a 50\% higher rate than the sample average and at several times the rate of "School B" graduates.

Note that I treat everyone with a tenure-track appointment at a given institution the same, whether they work in the department of economics, the business school, or elsewhere. This is because I do not always know for sure what department a person works in, because some universities' primary economics departments are within business school anyway, and, most importantly, because the institutional rankings do not distinguish between departments within schools. I hope this merely introduces some measurement error and attenuates any effects. ${ }^{11}$

\footnotetext{
${ }^{11} 57 \%$ of the person/years in the dataset are employment at a college or university, though only $43 \%$ are tenuretrack positions. Of the tenure-track academic jobs, $20 \%$ are in business schools, $1 \%$ in law schools, $2 \%$ in public
} 


\begin{tabular}{lcccc}
\hline \hline & Total & School A & School B & School C \\
\hline Female & $21.2 \%$ & $26.8 \%$ & $22.7 \%$ & $22.5 \%$ \\
U.S. Undergraduate & $59.2 \%$ & $75.2 \%$ & $57.3 \%$ & $66.7 \%$ \\
NSF Graduate Fellowship & $11.5 \%$ & $3.1 \%$ & $0 \%$ & $36.4 \%$ \\
Sloan Dissertation Fellowship & $8.7 \%$ & $6.5 \%$ & $0 \%$ & $12.5 \%$ \\
First Job: & & & & \\
$\quad$ econphd.net rank & 161.6 & 163.5 & 294.3 & 113.9 \\
& $(144.8)$ & $(142.6)$ & $(111.3)$ & $(132.7)$ \\
Tenure-track ranked & $47.6 \%$ & $44.0 \%$ & $14.8 \%$ & $55.7 \%$ \\
$\quad$ Top 50 & $29.8 \%$ & $24.8 \%$ & $5.9 \%$ & $42.3 \%$ \\
All Job/Years: & & & & \\
$\quad$ econphd.net rank & 186.9 & 190.5 & 301.3 & 147.9 \\
& $(148.3)$ & $(146.0)$ & $(104.5)$ & $(146.7)$ \\
Tenure-track ranked & $41.8 \%$ & $38.8 \%$ & $13.3 \%$ & $50.1 \%$ \\
$\quad$ Top 50 & $25.5 \%$ & $20.5 \%$ & $5.9 \%$ & $37.2 \%$ \\
Publications: & & & & \\
$\quad$ First 10 years & 3.94 & 3.35 & 1.24 & 5.67 \\
& $(5.23)$ & $(4.67)$ & $(2.33)$ & $(6.74)$ \\
$\quad$ Average per person/year & 0.31 & 0.27 & 0.14 & 0.44 \\
& $(0.47)$ & $(0.46)$ & $(0.32)$ & $(0.59)$ \\
Total People & 2,393 & 420 & 172 & 537 \\
Total Person/years & 27,259 & 5,120 & 1,739 & 7,027 \\
\hline
\end{tabular}

Table 1: Economist Sample Summary Statistics. "econphd.net" rank is the average of the adjusted ranking provided on the econphd.net website. The rank is the number the school is ranked in the case of universities, fifty plus twice the ranking for non-academic institutions, and 350 for any institution that is not ranked. "Tenure-track ranked" is an indicator variable for whether the person holds a tenure-track position at a university that is listed on the "econphd.net" rankings. "Top 50 " is an indicator variable for holding a tenure-track position at a school that is ranked among the top 50 universities by econphd.net. The columns for "School A" - "School C" each display data on all students who went on the job market from each of three (anonymous) graduate institutions. 


\begin{tabular}{lccccccc}
\hline \hline Career Year & Sample & TTR & TTR in & TTR out & Top50 & Top50 In & Top 50 Out \\
\hline 1 & 2,325 & 1,122 & 1,122 & 0 & 707 & 707 & 0 \\
2 & 2,198 & 1,056 & 17 & 24 & 669 & 10 & 13 \\
3 & 2,078 & 1,004 & 23 & 19 & 637 & 17 & 13 \\
4 & 1,951 & 935 & 13 & 23 & 592 & 12 & 21 \\
5 & 1,840 & 862 & 20 & 37 & 540 & 12 & 29 \\
6 & 1,717 & 753 & 5 & 58 & 470 & 3 & 31 \\
7 & 1,590 & 680 & 15 & 35 & 418 & 13 & 30 \\
8 & 1,488 & 620 & 8 & 30 & 378 & 7 & 24 \\
9 & 1,378 & 558 & 5 & 25 & 336 & 3 & 24 \\
10 & 1,268 & 500 & 7 & 29 & 298 & 8 & 21 \\
11 & 1,150 & 443 & 2 & 20 & 255 & 0 & 21 \\
12 & 1,044 & 395 & 5 & 14 & 223 & 3 & 12 \\
13 & 956 & 366 & 8 & 12 & 203 & 6 & 8 \\
14 & 842 & 325 & 4 & 10 & 181 & 3 & 5 \\
\hline
\end{tabular}

Table 2: Economist Transitions. "TTR" is the total number of people holding tenure-track jobs at institutions ranked by econphd.net. "Top 50" is the number holding tenure-track jobs at econphd.net top 50 universities. The "in" columns list the number of economists who moved into the category a given number of years into his career and "out" columns list the number who moved out of the category. Sample size changes because the last observation for a given person is the 2003-2004 academic year.

An important part of the following analysis is to see how people transition to "better" and "worse" jobs over the course of their careers. Table 2 provides a sense of how much movement there is between quality tiers in this labor market. Upon leaving school, about half the sample starts a "TTR" position and 30\% start tenure track jobs in Top 50 departments. The movement in and out of these positions is quite slow after that, however. A few people transition out of these positions every year, with the outflow peaking at $6-8 \%$ in the years around the time tenure is granted. The transition into these positions is minimal with only $1-2 \%$ of any given person/year observation in either the TTR or Top 50 category being held by someone who did not hold such a position in the prior year. Given the lack of movement into or out of these positions, this seems like a market where the luck of initial conditions has the potential to matter.

Figure 1 graphs the basic supply and demand measures in the data. To insure consistency over the sample period, the graph is limited to the three schools for which I have CV books going back to the Fall of 1980 or before. The graph shows two of the proxies for demand (unemployment and total JOE listings). It also shows the level of "supply" as proxied by the number of economists

policy schools, and $4 \%$ are in other departments (including schools of public health, social work, medicine, education, consumer sciences, and international affairs, as well as departments of political science, sociology, and agricultural economics.) 


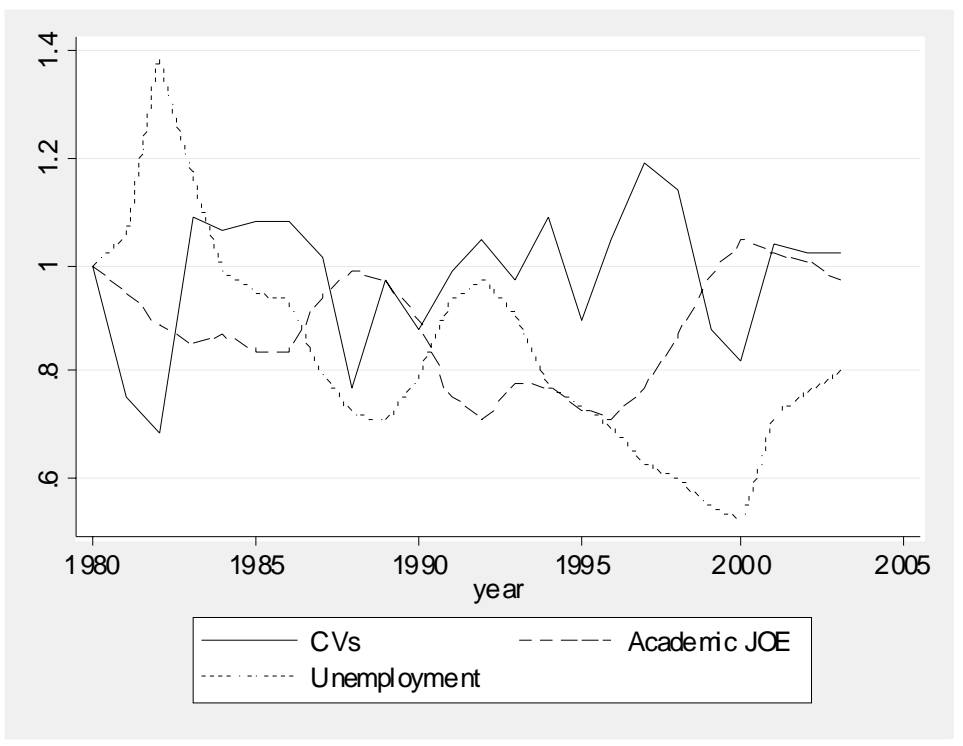

Figure 1: Proxies for Supply and Demand of Economists. All variables are normalized so that $1980=1$. "CVs" is the number of CVs in the job market books at the three schools that were available for all years. "Academic JOE" is the number of academic openings listed in Job Openings for Economists. "Unemployment" is the official U.S. unemployment rate for October.

listed in the CV books of the three schools. ${ }^{12}$ In the graph, year $t$ denotes October unemployment, the number of academic JOE listings during the year, and the number of CVs in the books sent out that Fall (that is, number of people seeking jobs starting in the Summer or Fall of year $t+1$.) All variables are normalized such that 1980 equals one.

As the graph shows, there are several periods of ups and downs in all these variables. ${ }^{13}$ This is important, as much of the following analysis is identified by inter-temporal variation in the measures of the state of the economy. During the early 1980's recession, unemployment spikes and JOE listings drop. Over the years shown, unemployment moves up and down considerably and the JOE listings generally move in the opposite direction at the same time. The correlation between the unemployment rate and JOE listings is -0.488 and is significantly less than zero at the 98\% confidence level. The correlation between the number of CVs in the books (or the number in the books for the first time) and the demand variables is insignificantly different from zero. This

\footnotetext{
${ }^{12}$ The book issued in the Fall of 1985 is missing for one of these schools. For that year, I assigned that one school the average number of students in its 1984 and 1986 books.

${ }^{13}$ I did not include the S\&P 500, academic job listings, and number of CVs in book for the first time in order to keep the graph simple. Similar conclusions can be drawn from these alternative supply and demand measures, though the S\&P 500 has only one long period of increase and one shorter down period.
} 


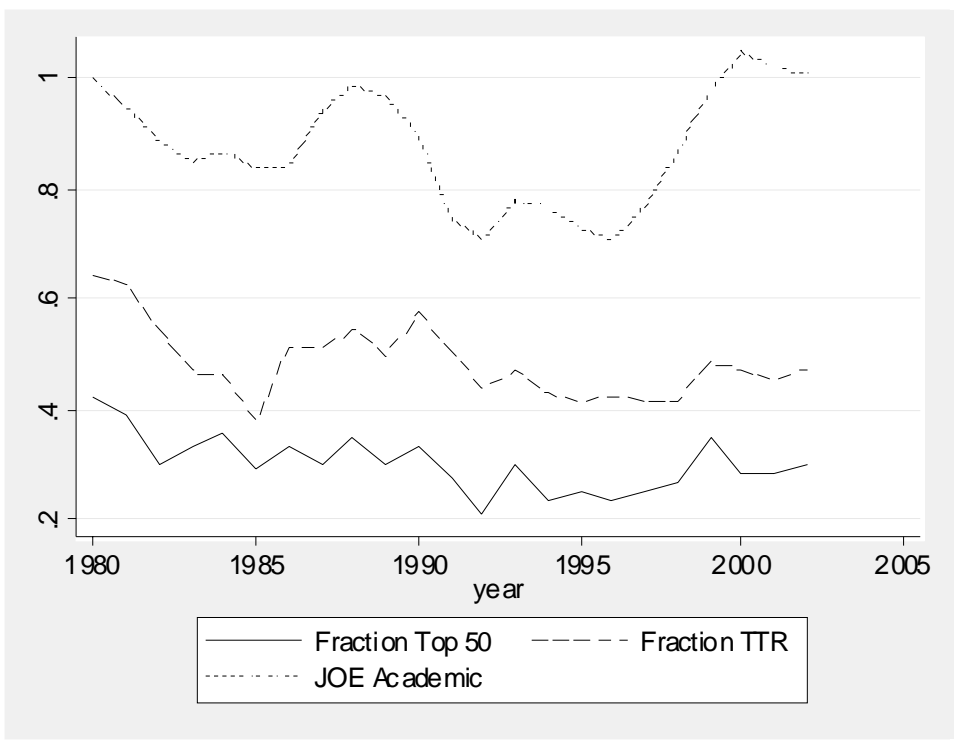

Figure 2: Macroeconomic Conditions and Initial Economist Placement. "Academic JOE" is the number of academic openings listed in Job Openings for Economists and is normalized so that 1980 $=1$. "Fraction TTR" is the fraction of initial placements into tenure track positions at schools ranked by econphd.net. "Fraction Top 50" is fraction of initial placements into tenure track positions at universities ranked in the top 50 by econphd.net.

provides some initial confidence that economists are not generally timing their decision of when to go on the market based on macroeconomic conditions.

\section{Cyclicality of Demand and Initial Job Placement}

Figure 2 shows the annual macroeconomic conditions, as proxied by total $J O E$ listings, with two measures of the quality of initial job market placement. The lines for the top 50 and tenure-track ranked variables are the proportion of people who were on the market for the last time in a given year that started jobs in these categories the following year. As the graph suggests, quality of placement is at least somewhat cyclical. Fewer graduates get "good" jobs during the early 1980's, 1990's, and 2000's recessions than in surrounding years. Figure 3 shows similar (though noisier) trends for graduates of one of the programs.

To see this relationship between macroeconomic conditions and initial job placement more formally, consider economist $i$ entering the labor force in year $t$. At the time he looks for a job, potential employers have a common estimate of his ability, $\alpha_{i}$. The number of positions available are exogenously determined by the state of the economy, $\theta_{t}$. All else equal, an economist who enters 


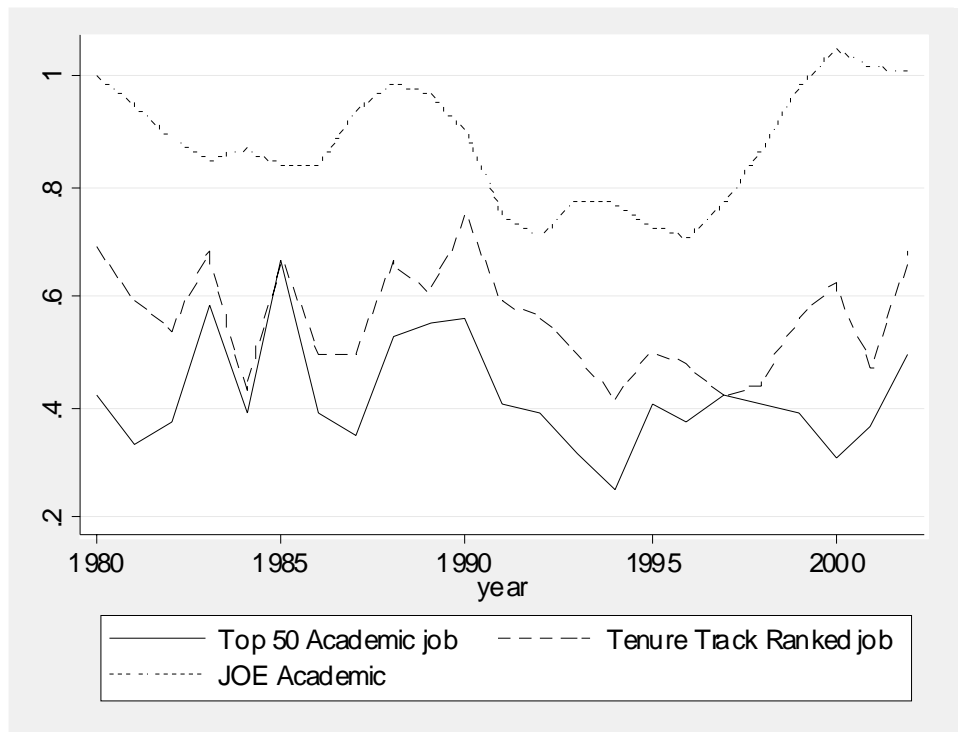

Figure 3: Macroeconomic Conditions and Initial Economist Placement - School C. See notes to Figure 2 for details.

the job market when $\theta_{t}$ is relatively high will get as good, or better, a job than an economist with equal $\alpha_{i}$ who enters when $\theta_{t}$ is low. Given this, I model the initial placement of economists as

$$
q_{i t}=\alpha_{i}+\delta \theta_{t}+\beta X_{i t}+\varepsilon_{i t}
$$

where $q_{i t}$ is one of the measures of the quality of a job taken by economist $i$ in year $t, X$ is a set of characteristics that affect demand for economists (which includes indicators for individual schools and a linear time trend), and $\varepsilon_{i t}$ reflects unobserved factors (such as geographical preferences or individual preference for money relative to an academic lifestyle).

Because there is only one observation for initial placement for each person, the ability term $\left(\alpha_{i}\right)$ is part of the error term when estimating equation (1). The estimated effects of macro conditions on initial placement $\left(\theta_{t}\right)$ will be unbiased as long as supply is not related to the state of the economy. This requires that the average quality of economists not vary systematically with $\theta_{t}$. Given that the quantity (and, many economists agree, quality) of applicants to graduate programs varies with macroeconomic conditions, it might seem plausible that conditions when leaving graduation school could also be related to quality of the outgoing class. I consider this issue in more detail below. Generally, I believe it is safe to assume that $\theta_{t}$ for an economist on the job market cannot be predicted by conditions when the economist entered school due to the four-plus years in between 


\begin{tabular}{lccc}
\hline \hline Dependent Variable & $\begin{array}{c}\text { econphd.net Rank } \\
\text { OLS } \\
\text { Specification }\end{array}$ & $\begin{array}{c}\text { TTR } \\
\text { Logit } \\
(1)\end{array}$ & $\begin{array}{c}\text { Top 50 } \\
\text { Logit } \\
(2)\end{array}$ \\
\hline Academic JOE listings & -73.42 & 0.270 & 0.293 \\
& $(23.29)$ & $(0.053)$ & $(0.051)$ \\
Year (trend) & -0.090 & -0.003 & -0.002 \\
& $(0.397)$ & $(0.001)$ & $(0.001)$ \\
$R^{2}$ (or pseudo $\left.R^{2}\right)$ & 0.0933 & 0.0383 & 0.0545 \\
$\mathrm{~N}$ (People) & 2,309 & 2,309 & 2,309 \\
\hline
\end{tabular}

Table 3: Quality of Initial Placement. Each of the dependent variables is a measure of the quality of the job held in the academic year after the person last appears in his school's CV book. The sample is limited to people who appear in two or fewer CV books. "econphd.net Rank" is econphd.net's ranking of the institution, adjusted as described in Table 1 and in the text. "TTR" is an indicator for tenure-track ranked position. "Top 50" is a tenure-track position at a school in econphd.net's top 50. See text and notes to Table 1 for more details on each of these variables. All columns include school fixed effects. "JOE listings" is the number of academic jobs listed in Job Openings for Economists in the calendar year when the CV book was sent out divided by the number listed in 1980. Unemployment rate is the U.S. unemployment rate for October of the year the CV book was sent out. In columns 2 and 3, coefficients are marginal effect on probability. Standard errors (in parentheses) are adjusted for correlation within year.

and/or that variation in the time it takes to get through graduate school insures $\theta_{t}$ is orthogonal to average $\alpha_{i}$ in a given class. ${ }^{14}$

The results of estimating (1) using three measures of $q_{i t}$ are displayed in Table 3. Column (1) shows results from an OLS regression where the dependent variable is the adjusted rank defined in Section 3. A lower number indicates a higher quality institution (at least as measured by "econphd.net.") The graduate school indicators, which are included in the regression and not displayed, are economically and statistically significant. Placement success varies systematically across these seven $\mathrm{PhD}$ programs. The year trend is insignificant, suggesting that the average ranking of the hiring institutions did not change over the course of the sample.

The negative coefficient on "Academic JOE listings" indicates that the average economist is hired by a higher-ranked institution when the demand for economists (as proxied by JOE listings) is relatively high. This relationship is significant at the $2 \%$ level. The -73.42 coefficient in column (1) indicates that, other things equal, when the number of academic JOE listings grows by $10 \%$ of

\footnotetext{
${ }^{14}$ The evidence in favor of this assumption includes that the number of CVs in a given school's packet is not related to demand conditions, the fact that the number of academic listings in $J O E$ is not correlated with the fraction of people on the job market that have a publication by the time they finish school, and, as discussed below, the fact that macroeconomic conditions when entering $\mathrm{PhD}$ studies is not correlated with job market success.
} 
the 1980 listings (which was slightly above the sample average for number of listings), the average economist's first institution will rank about seven places higher than it otherwise would have. This is equivalent to getting a job at the University of Illinois at Urbana-Champaign rather than at the University of Southern California, at Tulane rather than Oregon State University, or at the Federal Reserve Bank of Cleveland rather than at the Inter-American Development Bank.

Columns (2) and (3) show results from fitting a logit-equivalent version of (1). The dependent variables are indicator variables for holding a tenure-track job at a ranked institution and holding a tenure-track job at a top 50 institution. The positive and significant coefficients on the JOE variable indicates that economists are more likely to get jobs in these desirable categories when conditions are favorable. The coefficients indicate that an increase in JOE listings by $10 \%$ of the 1980 total increases the probability of each of these outcomes by about 3.0\%. This is a large effect, given an unconditional probability of about a half for TTR and about a quarter for Top 50.

In unreported regressions, I also found that the unemployment rate and the return on the S\&P 500 predict initial placements. However, these effects generally become insignificant when controlling for the more economist-specific JOE measure. I also found suggestive evidence that non-academic demand for economists makes academic jobs less attractive. When controlling for academic JOE listings, non-academic JOE listings are associated with "worse" values of the placement measures in Table 3. However, this effect is only marginally significant.

To test the potential problem that quality of graduating PhD's is driven by conditions when they enter graduate programs, I also performed a set of regressions similar to those in Table 3 with proxies for macroeconomic conditions when economists began their programs. In most cases, I do not have the exact date they began graduate studies. However, I used macroeconomic conditions five years before the person went on the job market and conditions when they finished undergraduate studies. I used the unemployment rate and academic JOE listings in each of these years as proxies for macroeconomic conditions. None of these proxies ever showed a significant relationship to rank of first job, whether the first job was a TTR position, or whether it was a Top 50 position.

The estimates in Table 3 suggest that macroeconomic conditions have a large effect on the likelihood of candidates obtaining desirable academic positions. Under the assumption that macroeconomic conditions are orthogonal to average ability of economists on the job market, it appears that "luck" plays a large part in the initial placement of economists. The next section investigates the degree to which this effect wears off as macro conditions change over economists' careers. 


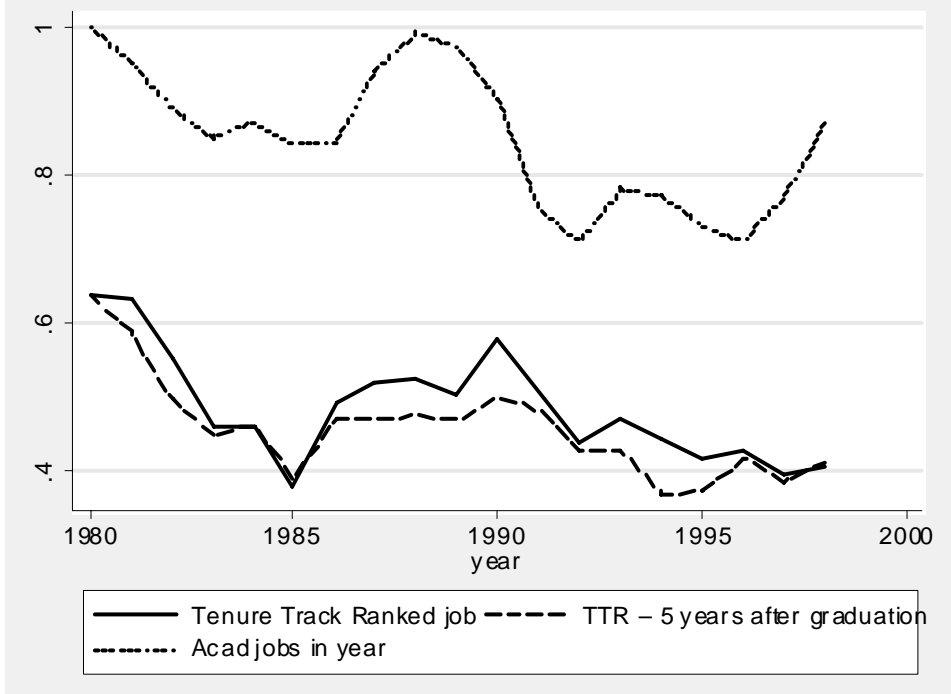

Figure 4: Macroeconomic Conditions, Initial Placement, and Longer-Term Placement

\section{Initial Macroeconomic Conditions and Long-term Outcomes}

\subsection{Long-term Job Quality}

To get an initial sense of the degree to which good initial jobs are related to long-term good jobs, Figure 4 graphs the $J O E$ listings macroeconomic proxy, the fraction of people in each class with initial jobs at tenure-track ranked institutions, and the fraction that hold such jobs five years after the last time they are in their graduate institution's CV book. The graph shows that the proportion holding tenure-track ranked jobs five years after graduation in any given year is closely related to the fraction that hold such jobs immediately after graduation. This could reflect unobserved variation in quality across classes. However, because the fraction with initial good placement is also related to macroeconomic conditions, there is some reason to believe that initial macro conditions have lasting effects. Figure 5 shows a similar graph for a single school. As with the broader group of economists from seven schools, the relationship between initial and five-year placement is close. However, because this relationship is not obviously closer than it is for the market as a whole, differences in unobserved quality are unlikely to explain the relationship alone because it would seem logical to expect these effects to be stronger within school-years than within a year across a group of schools.

Figure 6 provides another graphical perspective on the development of cohorts' careers. It shows the fraction of any given graduating class that holds a tenure track ranked job initially, four years 


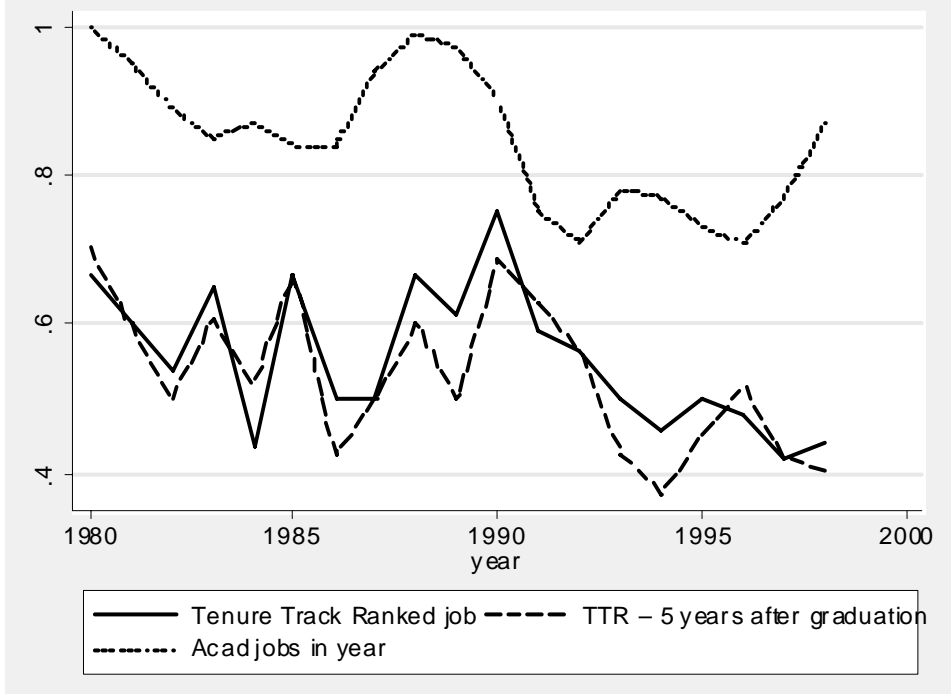

Figure 5: Macroeconomic Conditions, Initial Placement, and Longer-Term Placement - School C

after graduation, eight years after, and twelve years after. In the graph, the x-axis represents the Fall of the year the person's CV last appeared in his/her institution's CV book. For any given year on the x-axis, the points on the lines represent the fraction of people in that job market year that held tenure-track ranked jobs some number of years after leaving school. The graph shows that the relationship between initial and later outcomes is always strong but fades over the twelve year interval.

I now more formally address the question of to what extent does obtaining a "good" first job affect the probability of holding a good job at some future date? I start by updating equation (1) for an economist who has been out of school for a number of years. Consider economist $i$ who went on the job market in year $m$ and holds a job in year $t$. I model his current position as

$$
q_{i t}=\alpha_{i}+\delta \theta_{t}+\beta X_{i t}+\phi q_{i m}+\varepsilon_{i t}
$$

There are two differences between (1) and (2). First, because the person has worked for a number of years, the set of variables in $X$ has evolved. I now control for graduate school, indicators for year of observation $(t)$, indicators for years of experience $(t-m)$, and a linear trend for year entered labor market $(m)$.

The more important difference between (1) and (2) is $\phi$, which is the effect of the quality of the initial job on the current job. This parameter cannot be estimated by OLS (or, in the case of 


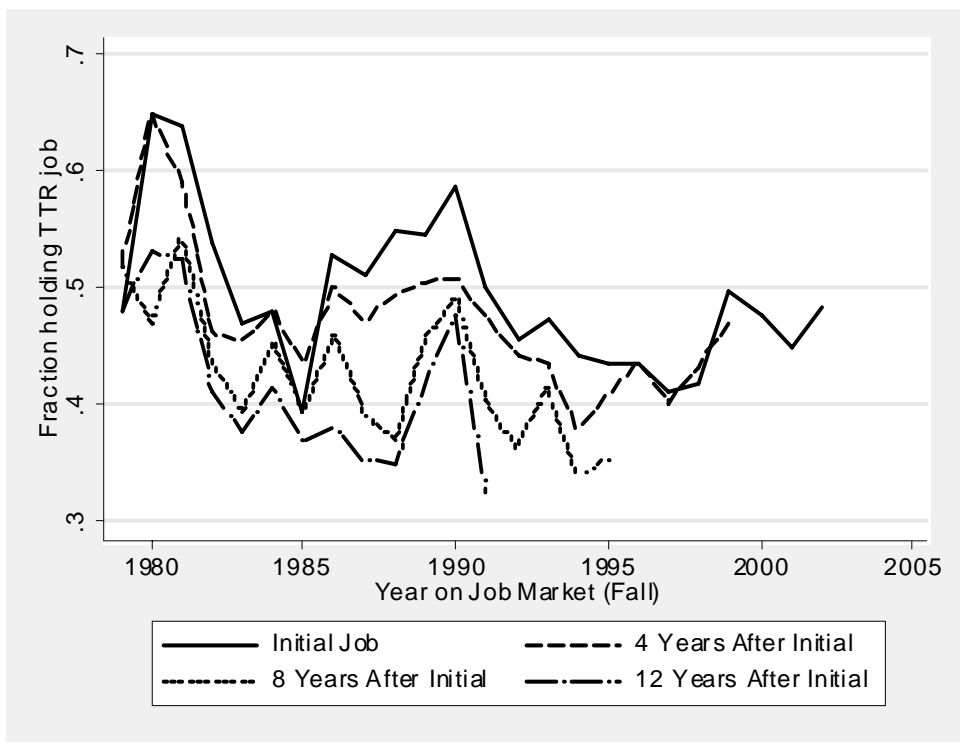

Figure 6: Career Progression of Cohorts. The graph is limited to the three schools for which data is available over the entire sample period. Each line shows the fraction of each graduating cohort that holds a tenure-track job at a ranked university some number of years after seeking initial placement.

discrete measures of $q$, by a logit), however. Given that I do not observe $\alpha$ and that it will surely be the case that $\operatorname{corr}\left(q_{i m}, \alpha_{i}\right) \neq 0$, the OLS estimate of $\phi$ will not capture the causal effect of a change in the initial job. Even though I have multiple observations for each person, I cannot use person-specific fixed effects to estimate $\phi$ because $q_{i m}$ does not vary across observations for the same person.

Though a causal interpretation of estimates of (2) requires using instrumental variables, I start with standard OLS and logit analyses to establish the baseline determinants of $q_{i t}$ and to use for comparison in later analyses that include instruments. Table 4 shows results from this analysis, using three of the job quality measures as dependent variables. In these regressions, an observation is a person/year at least three years after the person went on the job market for the last time. Panel A shows OLS regressions where the dependent variable is the adjusted econphd.net rank. The other panels show logits where the dependent variable equals one in any year where the person holds a tenure-track position at a ranked institution (Panel B) or holds such a position at a Top 50 university (Panel C.)

Column 1 shows that economists who graduate when $J O E$ listings are relatively high are more likely to have a "good" job at any year in the sample. In fact, the coefficients are quite similar to those for initial placement in Table 3, though the coefficient in the Panel A regression is not 


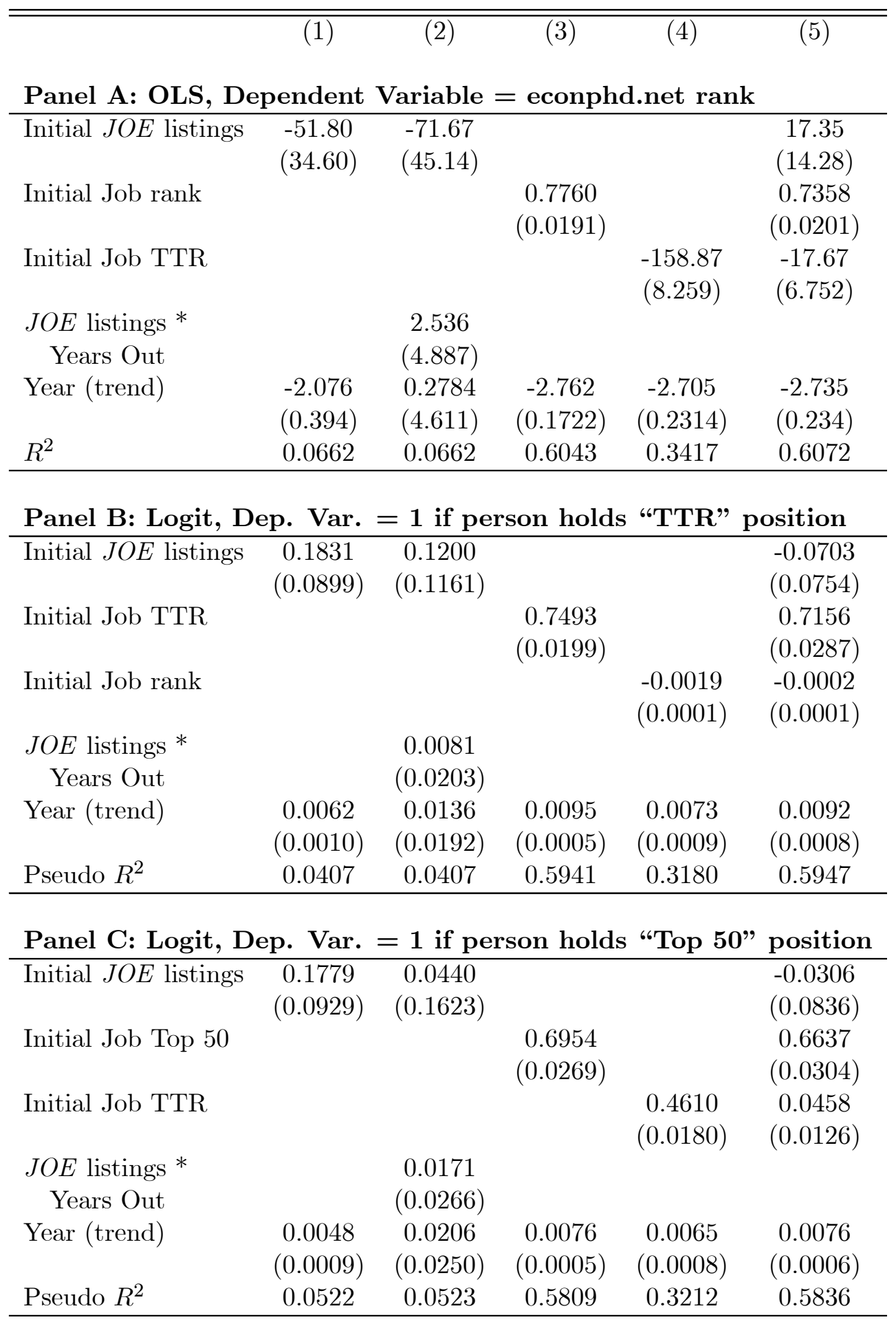

Table 4: Quality of Longer-Term Job. On observation is a person/year at least three years after the person last goes on the job market. In each regression, there are 18,994 observations covering 1,951 people. The sample is limited to people who appear in two or fewer CV books. See Table 3 for definition of dependent variables and "JOE listings." All columns include school fixed effects, year of observation fixed effects, and indicators for every possible number of years from when the person went on the market to the observation. Standard errors (in parentheses) are adjusted for any correlation within year. 
statistically significant. In column 2, I include an interaction between the JOE listings and the number of years from the time the person is last on the job market to the observation $(t-m)$. If the effect of initial conditions wears off, this coefficient would indicate that the relationship between initial conditions and job quality gets smaller over time. This would be reflected by a positive coefficient on the interaction variable in Panel A and a negative coefficient in Panels B and C. However, the interaction variable is imprecisely estimated and insignificant in all three panels suggesting that there is no strong evidence that the effects estimated in Table 3 wear off over economists' careers.

Columns 3-5 show the relationship between initial job quality and longer-term job quality. Column 3 shows how each initial quality measure is related to that same measure for longer term outcomes. In all cases, the relationship is quite strong and, in the case of TTR, suggests a onefor-one correspondence between initial job quality and later quality. These effects make the JOE listings variable coefficient insignificant, as shown in Column 5.

A naive interpretation of the results in Columns 3-5 would be that getting a good initial job leads to good later jobs. However, the only way to make a causal interpretation of $\phi$ is to find an instrument that is exogenous with respect to $q_{i m}$ and only affects $q_{i t}$ through its effect on $q_{i m}$. That is, I need an exogenous variable that affects economists' initial position but only affects later outcomes through its effect on initial conditions. Fortunately, several candidates are available.

The first instrument is the $J O E$ listings variable used in Table 3. From that Table, it is clear that the $J O E$ variable has a meaningful effect on initial placement. I can see no reason why the $J O E$ listings when the person initially entered the labor market would affect later outcomes other than through its effect on initial placement. So, as long as the standard assumptions for OLS estimation of $\theta_{t}$ in (1) hold (and also allowing for correlation of outcomes for people on the market in a given year), JOE listings should be a valid instrument for $q_{i m}$ when estimating (2).

The second set of instruments is the unemployment rate, S\&P 500 level, and S\&P 500 return variables. While these variables have the advantage that they are unrelated to the market for economists and, therefore, potentially more clearly exogenous with regard to $q_{i m}$, they have the disadvantage that they provide less precise estimates of initial placement. That is, these instruments are weaker than the $J O E$ listings instrument.

I also use indicator variables for market-entry years as instruments. This provides a more flexible specification for effect of individual years on initial conditions relative to the $J O E$ variable. However, the validity of these instruments requires a stronger assumption. Specifically, market entry year is only a valid instrument if the year of entry only affects later positions through its effect on initial placement. A very strong interpretation of this assumption requires that, controlling 
for school and years of experience, average economist ability does not differ across the years in the sample. The instrument is also valid under the weaker assumption that demand for economists is inelastic with respect to quality of the new economists available on the market. If schools are allotted a certain number of "slots" in a given year and they fill those slots regardless of supply quality, this assumption will hold. ${ }^{15}$

Table 5 shows IV results using the same dependent variables as in Table 4. All three panels report results from two-stage least squares (so the Panel B and $\mathrm{C}$ results are linear probability estimates. $)^{16}$ Columns 1 and 2 use academic JOE listings as the instrument for initial placement. In all three cases, the initial placement measure that matches the dependent variable generates the more precise result. But in all six regressions, the point estimate indicates that initial conditions matter. That is, if $J O E$ listings is a valid instrument, it appears that getting a good initial job has a causal effect on having a good job later. The Panel B, column 1 estimate suggests that holding a TTR position right after leaving school raises the probability of holding one in a later year by $55 \%$. Given an unconditional probability of about 50\%, this is a huge effect. The Panel A, column 1 estimate suggests that holding an initial job that ranks one place higher initially leads to holding a job that ranks 0.6 places higher in a later year. Panel C, column 1 shows that an initial Top 50 job increases the probability of holding one later by over $60 \%$.

The estimates using the other macro variables as instruments for initial job lead to similar, though less precisely estimated, coefficients. The estimates in column 4, which use the job market year indicators as instruments, are also similar and they are estimated quite precisely. Though the assumption underlying the validity of this set of instruments is more debatable, the fact that the results are similar across all specifications provides some degree of comfort.

The evidence in the tables and graphs to this point are consistent with the notion that starting conditions have a large impact on economists' careers. The transition probabilities, the importance of macro conditions on initial conditions, and the correlation between initial conditions and longterm outcomes all suggest that seasoned economists are far more likely to hold a "good" job if they start with a "good" job. The IV estimates in Table 5 imply that this relationship is strong and causal.

One concern with the estimates in Table 5 is that they include multiple observations on the

\footnotetext{
${ }^{15}$ While the year instruments have the most explanatory power in the first stage regressions, they use up the most degrees of freedom. Therefore, these first stage regressions have lower F-statistics than when I use the JOE or macro instruments. The first-stage F-statistics in the IV analyses in the rest of this section vary from 12.4 to 32.9 . In the next section, where I reduce the size of the dataset considerably, the first-stage F-statistics vary from 3.9 to 16.9 .

${ }^{16}$ I use linear probability two-stage least squares because it is relatively simple to implement, makes interpretation easier, and, according to Angrist (2001), is an appropriate empirical approach in contexts such as this.
} 


\begin{tabular}{|c|c|c|c|c|}
\hline & $(1)$ & $(2)$ & $(3)$ & $(4)$ \\
\hline \multicolumn{5}{|c|}{ Panel A: 2SLS, Dependent Variable = econphd.net rank } \\
\hline \multirow[t]{2}{*}{ Initial Job rank } & 0.6024 & & 0.5460 & 0.7551 \\
\hline & $(0.1794)$ & & $(0.2751)$ & $(0.1060)$ \\
\hline \multirow{2}{*}{\multicolumn{2}{|c|}{ Initial Job TTR }} & -155.53 & & \\
\hline & & $(85.26)$ & & \\
\hline \multirow[t]{2}{*}{ Year (trend) } & -2.558 & -2.697 & -2.443 & -2.733 \\
\hline & $(0.338)$ & $(0.626)$ & $(0.435)$ & $(0.209)$ \\
\hline Instrument(s) & JOE & JOE & Macro & Job Market Year \\
\hline \multicolumn{5}{|c|}{ Panel B: 2SLS, Dep. Var. = 1 if person holds "TTR" position } \\
\hline \multirow[t]{2}{*}{ Initial Job TTR } & 0.5499 & & 0.5496 & 0.6643 \\
\hline & $(0.2232)$ & & $(0.3063)$ & $(0.1562)$ \\
\hline \multirow{2}{*}{\multicolumn{2}{|c|}{ Initial Job rank }} & -0.0021 & & \\
\hline & & $(0.0011)$ & & \\
\hline \multirow[t]{2}{*}{ Year (trend) } & 0.0084 & 0.0079 & 0.0083 & 0.0079 \\
\hline & $(0.0015)$ & $(0.0017)$ & $(0.0019)$ & $(0.0011)$ \\
\hline Instrument(s) & JOE & JOE & Macro & Job Market Year \\
\hline \multicolumn{5}{|c|}{ Panel C: 2SLS, Dep. Var. } \\
\hline \multirow[t]{2}{*}{ Initial Job Top 50} & 0.6111 & & 0.4176 & 0.5593 \\
\hline & $(0.2949)$ & & $(0.1758)$ & $(0.1405)$ \\
\hline \multirow{2}{*}{\multicolumn{2}{|c|}{ Initial Job TTR }} & 0.5343 & & \\
\hline & & $(0.2432)$ & & \\
\hline \multirow[t]{2}{*}{ Year (trend) } & 0.0086 & 0.0069 & 0.0060 & 0.0068 \\
\hline & $(0.0016)$ & $(0.0017)$ & $(0.0011)$ & $(0.0007)$ \\
\hline Instrument(s) & JOE & JOE & Macro & Job Market Year \\
\hline
\end{tabular}

Table 5: Quality of Longer-Term Job. An observation is a person/year at least two years after the person last goes on the job market. In each regression, there are 18,994 observations covering 1,951 people. The sample is limited to people who appear in two or fewer CV books. In each column, the measure of initial placement is instrumented using the listed set of instruments. See Table 3 for definition of dependent variables and "JOE". "Other Macro" indicates the S\&P 500 level and one-year return as of the end of October and the October unemployment rate of the year the CV book was distributed. All columns include school fixed effects, year of observation fixed effects, and indicators for every possible number of years from when the person went on the market to the observation. Standard errors (in parentheses) are adjusted for any correlation within year. 
same people. While I took the more conservative approach of clustering for within-graduatingcohort correlation, the standard errors could be understated due to within-person correlation across years. I also ran these regressions looking at a single point in careers (such as five years after leaving school or ten years after leaving school.) The results are generally similar, though the statistical significance varies from year to year (and across instrument choice.) For years further from graduation, the effects dissipate somewhat and (because the sample size decreases when I condition on a higher number of years since leaving school) become noticeably less precise.

These results have several implications. First, they suggest that a fledgling economist who wants to spend his career at a leading institution can increase the odds of that occurring by looking for a first position when job market conditions are favorable. As the large "local average treatment effect" literature highlights, the estimates in Table 5 do not apply to all economists. Rather, these estimates should be thought of as relevant to those whose initial placement is affected by the state of job market. There is probably a very small set of superstars that would get offers from top institutions in any year and a larger subset of economists that would never be a good match for an academic research environment. However, for the potentially large group whose first job might be driven partially by macroeconomic conditions, the evidence suggests that starting conditions have a large causal impact on economists' careers.

Second, an underlying assumption of this analysis is that people would generally agree that job quality is represented by econphd.net or other rankings. Naturally, there are variations in geographical preferences, research styles, and other things that affect happiness on the job. But preferences and skills evolve over careers. Those economists who, because of bad timing, end up at lower ranked schools where they invest in teaching rather than research skills might find it hard to move to a more research-focused school. Their comparative advantage in teaching may make it efficient and preferable for them to stay at their initial employer even if "better" opportunities arise. That is, economists may invest in what Gibbons and Waldman (2004) call "task-specific human capital" and, conditional on initial placement, may obtain higher utility by staying with their first employer than switching to a school that they would have preferred initially.

Finally, none of the analysis to this point has uncovered the reasons for these cohort effects. Is it simply the case that preferences evolve and/or that the costs of moving positions is too high? Or do economists who get better initial positions "deserve" better positions later because they obtain more human capital? Though I will not be able to determine exactly which factors create the cohort effects, I can at least narrow down the possibilities by determining if initial placement affects economist productivity. The next section explores this issue by examining the relationship between research output, initial placement, and later placement. 


\subsection{Research Productivity}

I now consider how initial placement affects research output. As discussed in Section 2, some theories that are consistent with the long-term effects of initial jobs demonstrated in the last section predict that initial placement will affect productivity. Others do not predict a direct effect of first job on productivity. By using publishing activity as a measure of productivity, I can take some steps towards discriminating among possible explanations for long-term effects of initial jobs.

I gathered information on economist productivity by compiling a list of all journal article publications of each economist listed in the online version of "EconLit." Economists in the career sample were matched to EconLit using full names. I hand checked any outliers where a person had many publications but did not have a research job or few publications but worked at a top institution. These cases usually were rectified after determining that there were multiple economists with the same name ${ }^{17}$ or that the person publishes under a slight variant from the name on their job market CV. However, there is likely to be at least some (hopefully innocuous) measurement error.

I define a categorical variable, which I will call "publication group", that equals zero for those who have never published (37\% of the sample after ten years), one for those with one or two publications $(19 \%)$, two for those with three to five publications $(17 \%)$, three for those with six to ten $(17 \%)$, four for those with eleven to twenty $(9 \%)$, and five for those with more than twenty (the remaining 1.5\%.) This categorization was based on a taste for round numbers and the fact that it seemed to break people into groups one might reasonably describe as "superstars", "stars", "solid research contributors", and so on to those who never published. It was the only categorization that I tried. Figure 7 shows the distribution of publication counts ten years after leaving school (both the density function and the cumulative distribution).

I also created an indicator variable that I will call "Big 5" that equals one if the person has ever published a paper in one of the journals generally considered to be the top five general interest journals. These include the American Economic Review, Econometrica, the Journal of Political Economy, the Quarterly Journal of Economics, and the Review of Economic Studies. ${ }^{18}$

The analysis that I discuss in the text and that is displayed in Table 6 is based on publication category and the Big 5 indicator. In addition to these variables, I also did analyses where I defined the dependent variable as the total number of papers, the number of papers in Big 5 journals, publications in the journals econphd.net includes in compiling its rankings, and publications ranked

\footnotetext{
${ }^{17}$ Kevin Murphy and John Roberts are especially problematic economist names.

${ }^{18}$ Though these journals are more commonly known as the "Top 5", I use "Big 5" to minimize potential confusion with the "Top 50" university variable.
} 


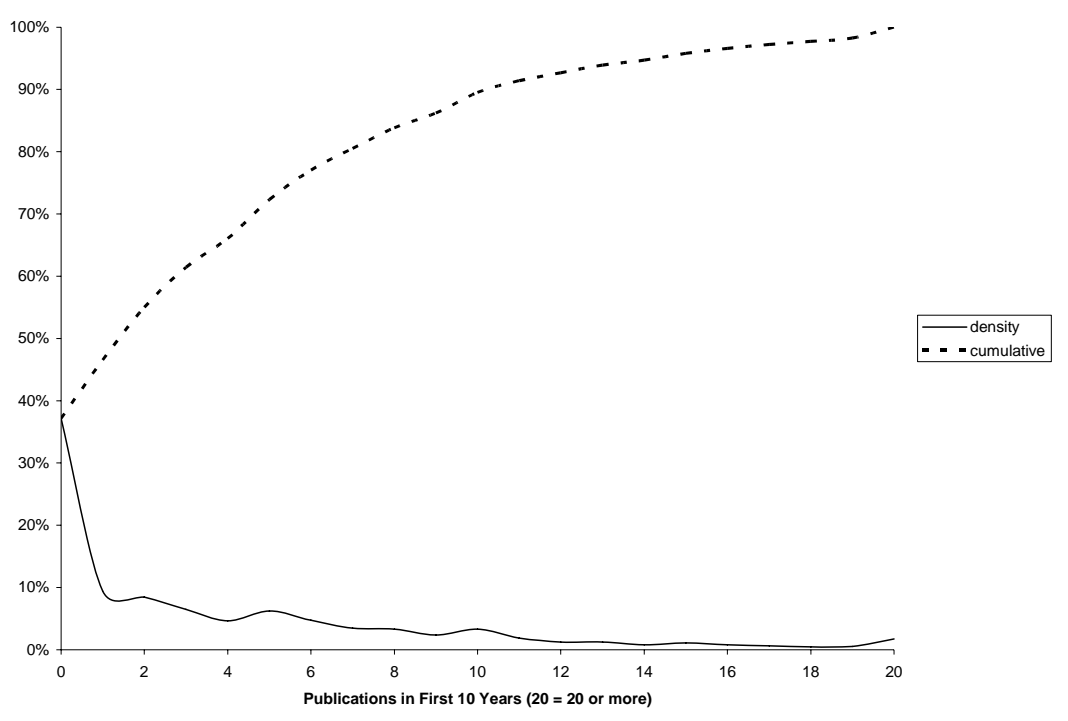

Figure 7: Publication Distribution. The sample is limited to economists ten years after leaving school. The solid line indicates the proportion of the sample that have each possible number of publications, with twenty including those with twenty or more. The dotted line shows the cumulative distribution, so it indicates the percentage of the sample with a given number of publications or fewer.

in Kalaitzidakis et al. (2003). The results were quite similar to those presented below. One might argue that citations is a better measure of productivity than publications. However, I was only able to gather information on number of citations at the present time and so it is not possible (at least not at reasonable cost) to get a consistent measure of citations over a person's career.

The analysis of publications is similar conceptually to the analysis of long-term jobs. I regress publication records as of some number of years after leaving school on measures of the quality of a person's first job and/or measures of demand for economists when the person went on the job market. ${ }^{19}$ I then instrument for quality of first job with macro variables that were shown to affect first placement in Section 4, but that should not affect research productivity other than through their effect on initial placement. I also instrument for initial placement with a full set of indicator variables for the year the person went on the job market.

Unlike the long-term placement regressions above, I only use one observation per person in any given regression. This is because any measure of publications should include the "stock" of

\footnotetext{
${ }^{19}$ Grove and $\mathrm{Wu}(2006)$ also study factors that are correlated with economists' research output. They focus on variables that are observable from graduate school applications. Unless there is some imperfection in the economist labor market, the effects of these variables should be captured by the quality of initial placement and the state of the job market.
} 
publications to date (at least over the number of years I analyze here). In picking the number of years after the person leaves school, there is an important trade-off between reducing the noise publication lags create in early career publication counts against the fact that each year I wait requires throwing one graduating class out of the data. I ended up settling on ten years. The relationship between job quality and publications is non-existent when using seven years and a bit stronger when using twelve years. The mean, median, and mode publications ten years after going on the job market are 3.9, 2, and zero, respectively.

Each regression controls for a linear trend in calendar years because, as publication cycles and paper complexity have increased over time (see Ellison (2002b) and Ellison (2002a)), this should lower publication counts at any given point in people's careers. Controlling for year squared and year to the third power generally increases the estimates of the effects of interest in the following analysis, but also increases standard errors.

Panel A of Table 6 shows the results of IV regressions where the dependent variable is the publication category. The odd columns attempt to isolate the causal effect of a good first job on publications by using macro conditions to instrument for the first job. The even columns use year indicators as instruments. All point estimates lead to the conclusion that there is a strong causal effect of getting a good first job on publications. Putting the coefficients in some perspective, the estimates in columns (1) and (2) indicate that getting a job at, for example, BU rather than Washington University leads a person to move up by 0.1-0.2 publication categories. It is hard to put this number into an exact figure, but it is roughly an extra paper for someone who publishes 10-15 papers in ten years.

Panel B shows results where the dependent variable is an indicator for a Big 5 publication. The estimates using adjusted rank show a small effect, which is likely due to the fact that publication in these journals is rare and is heavily concentrated at highly ranked schools. However, the estimates in columns (5) and (6) indicate that placement at BU, for example, increases the probability of publishing a Big 5 paper by $50 \%$ relative to a job ranked outside the Top 50 .

The results of the analysis are consistent and suggest that the productivity effect of getting a good first job are large. However, the results are not overwhelming in terms of statistical significance. The evidence suggests that there is a causal effect of getting a good first job on publication records and that at least some of the long-term effects of getting a good initial placement as an economist are due to this placement making the person more productive. This rules out a very strict form of influence activity, asymmetric information, or search cost models being the primary reason for long-run effects of initial job placement. The evidence seems consistent with the idea that economists develop "task-specific" human capital as in Gibbons and Waldman (2006). Those 


\begin{tabular}{|c|c|c|c|c|c|c|}
\hline & (1) & $(2)$ & $(3)$ & $(4)$ & $(5)$ & $(6)$ \\
\hline \multicolumn{7}{|c|}{ Panel A: Dependent Variable = Publication category after 10 years } \\
\hline Initial Job rank & $\begin{array}{c}-0.0077 \\
(0.0059)\end{array}$ & $\begin{array}{c}-0.0036 \\
(0.0016)\end{array}$ & & & & \\
\hline Initial Job TTR & & & $\begin{array}{c}1.4796 \\
(0.9277)\end{array}$ & $\begin{array}{c}1.0682 \\
(0.5808)\end{array}$ & & \\
\hline Initial Job Top 50 & & & & & $\begin{array}{c}1.9028 \\
(1.2736)\end{array}$ & $\begin{array}{c}1.6200 \\
(0.6725)\end{array}$ \\
\hline Year (trend) & $\begin{array}{l}-0.0124 \\
(0.0083)\end{array}$ & $\begin{array}{c}-0.0239 \\
(0.0084)\end{array}$ & $\begin{array}{l}-0.0124 \\
(0.0083)\end{array}$ & $\begin{array}{c}-0.0144 \\
(0.0080)\end{array}$ & $\begin{array}{c}-0.0051 \\
(0.0111)\end{array}$ & $\begin{array}{l}-0.0079 \\
(0.0086)\end{array}$ \\
\hline Instrument & $J O E$ & Year & $J O E$ & Year & $J O E$ & Year \\
\hline Panel B: Depenc & ent Vari & ble $=1$ & at least & one "Biq & 5" pape & er 10 ye \\
\hline Initial Job rank & $\begin{array}{c}-0.0023 \\
(0.0021)\end{array}$ & $\begin{array}{c}0.0001 \\
(0.0004)\end{array}$ & & & & \\
\hline Initial Job TTR & & & $\begin{array}{c}0.4443 \\
(0.2287)\end{array}$ & $\begin{array}{c}0.3348 \\
(0.1521)\end{array}$ & & \\
\hline Initial Job Top 50 & & & & & $\begin{array}{c}0.5713 \\
(0.2582)\end{array}$ & $\begin{array}{c}0.4635 \\
(0.2721)\end{array}$ \\
\hline Year (trend) & $\begin{array}{l}-0.0063 \\
(0.0049)\end{array}$ & $\begin{array}{l}-0.0026 \\
(0.0028)\end{array}$ & $\begin{array}{l}-0.0010 \\
(0.0023)\end{array}$ & $\begin{array}{l}-0.0016 \\
(0.0023)\end{array}$ & $\begin{array}{c}0.0012 \\
(0.0032)\end{array}$ & $\begin{array}{c}0.0002 \\
(0.0036)\end{array}$ \\
\hline Instrument & $J O E$ & Year & JOE & Year & $J O E$ & Year \\
\hline
\end{tabular}

Table 6: Publication Records. An observation is a person ten after he/she last goes on the job market. The dependent variable in Panel A equals 0 if the person has no EconLit journal articles, 1 if he has 1-2 publications, 2 if he has 3-5, 3 if he has 6-10, 4 if he has 11-20, and 5 if he has more than twenty. The dependent variable in Panel B equals 1 if the person has published a paper in a "Big 5" journal (see text for journal list.) There are 1,259 observations in each regression. The sample is limited to people who appear in two or fewer CV books. Ranks, TTR, and Top 50 are defined in Table 3. The instruments are defined in Table 4. All regressions include school fixed effects. "Year" instruments is a set of indicator variables for the possible years of going on the job market. Standard errors (in parentheses) are adjusted for any correlation within year. 
who place at research-focused institutions develop research skills that lead to more publications. It could also be the result of peer effects from better colleagues or from initial job placement endogenously affecting economists' ambitions and preferences. Naturally, the true underlying model is probably some combination of these possibilities.

\section{Conclusions and Further Research}

At least among economists, "good" jobs are very persistent. Economists who work at top research jobs start at top research jobs. While some of this is because top universities hire researchers with obvious potential, some is just the luck of the job market when people graduate. Unfortunately, given the limits of the available data, it is impossible to say for sure how much luck matters relative to skill. I also cannot determine how much of the causal effect of initial placement on later placement is due to the increase in productivity other than to say productivity explains at least some of the effect. I hope to identify more details of how the market for economists works in future work, as I continue to improve the data and model the underlying labor market in more detail.

One implication of this study is that graduating economists who are not at the very top or very bottom of their cohort may reap long-term benefits by timing their market entry to coincide with a strong job market. But if that strategy became too common, the benefits of using it would likely diminish.

Another key lesson here is that those economists who, because of bad timing, end up at lower ranked schools may find it hard to move to a more research-focused school. In part, this may occur because they develop skills, perhaps especially teaching skills, which give them a comparative advantage with their initial employer even if "better" opportunities arise. That is, a typical economist may invest in what Gibbons and Waldman (2006) call "task-specific human capital" and, conditional on initial placement, may obtain higher utility by staying with the type of employer he first works for rather than switching to a type of institution that he would have preferred initially. It appears that initial job market luck affects top positions in academia, drives research productivity between neighboring cohorts of graduates, and may also move large amounts of wealth. 


\section{References}

Akerlof, George A., "The Market for Lemons: Quality Uncertainty and the Market Mechanism," Quarterly Journal of Economics, 1970, 109, 701-733.

Angrist, Joshua D., "Estimation of Limited Dependent Variable Models With Dummy Endogenous Regressors: Simple Strategies for Empirical Practice," Journal of Business and Economics Statistics, 2001, $19,2-28$.

Baker, George, Michael Gibbs, and Bengt Holmstrom, "The Internal Economics of the Firm: Evidence from Personnel Data," Quarterly Journal of Economics, 1994, 109, 881-919.

Beaudry, Paul and John DiNardo, "The Effect of Implicit Contracts on the Movement of Wages Over the Business Cycle: Evidence from Micro Data," Journal of Political Economy, 1991, 99, 665-688.

Brook, Kathleen and F. Ray Marshall, "The Labor Market for Economists," American Economic Review, 1974, 64, 488-511.

Coupe, Tom, "Revealed Performances: Worldwide Rankings of Economists and Economics Departments, 1990-2000," Journal of the European Economic Association, 2003, 1, 1309-1345.

_ _ Valerie Smeets, and Frederic Warzynski, "Incentives, Sorting and Productivity Along the Career: Evidence from a Sample of Economists," Journal of Law, Economics and Organization, 2006, 22, 137167.

Devereaux, Paul, "The Benefits of Obtaining a High-Paying Job," 2004. UCLA.

Ehrenberg, Ronald G., "Studying Ourselves: The Academic Labor Market," Journal of Labor Economics, 2003, 21, 267-287.

Einav, Liran and Leeat Yariv, "What Šs in a Surname? The Effects of Surname Initials on Academic Success," Journal of Economic Perspectives, 2006, 20. Forthcoming.

Ellison, Glenn, "Evolving Standards for Academic Publishing: A q-r Theory," Journal of Political Economy, 2002, 110, 994-1034.

_ - "The Slowdown of the Economics Publishing Process," Journal of Political Economy, 2002, 110, 947-993.

Frank, Robert H., "Are Workers Paid Their Marginal Products?," American Economic Review, 1984, 74, 549-571.

Gibbons, Robert and Michael Waldman, "Task-Specific Human Capital," American Economic Review, 2004, 94, 203-207.

_ and _ _ "Enriching a Theory of Wage and Promotion Dynamics Inside Firms," Journal of Labor Economics, 2006, 24, 59-107. 
Goyal, Sanjeev, Marco van der Leij, and Jose Luis Moraga Gonzalez, "Economics: An Emerging Small World," Journal of Political Economy, 2006, 114. Forthcoming.

Grove, Wayne A. and Stephen Wu, "The Search for Talent: Doctoral Completion and Research Productivity of Economists," American Economic Review, 2006, 96. Forthcoming.

Hamermesh, Daniel S., George E. Johnson, and Burton Weisbrod, "Scholarship, Citations and Salaries: Economic Rewards in Economics," Southern Economic Journal, 1982, 49, 472-481.

Hayes, Rachel M., Paul Oyer, and Scott Schaefer, "Co-Worker Complementarity and the Stability of Top-Management Teams," Journal of Law, Economics and Organization, 2006, 22, 184-212.

Kahn, Lisa B., "The Long-Term Market Consequences of Graduating College in a Bad Economy," 2005. Harvard University.

Kalaitzidakis, Pantelis, Theofanis P. Mamuneas, and Thanasis Stengos, "Rankings of Academic Journals and Institutions in Economics," Journal of the European Economic Association, 2003, 1, 13461366.

Lazear, Edward P., "Firm-Specific Human Capital: A Skill-Weights Approach," Working Paper 9679, National Bureau of Economic Research 2003.

Levin, Sharon G. and Paula E. Stephan, "Research Productivity Over the Life Cycle: Evidence for Academic Scientists," American Economic Review, 1991, 81, 114-132.

Milgrom, Paul R., "Employment Contracts, Influence Activities and Efficient Organization Design," Journal of Political Economy, 1988, 96, 42-60.

Neary, J. Peter, James A. Mirrlees, and Jean Tirole, "Evaluating Economics Research in Europe: An Introduction," Journal of the European Economic Association, 2003, 1, 1239-1249.

Oreopoulos, Philip, Till von Wachter, and Andrew Heisz, "Permanent and Transitory Effects from Graduating in a Recession," 2005. University of Toronto.

Oyer, Paul, "The Making of an Investment Banker: Macroeconomic Shocks, Career Choice, and Lifetime Income," Working Paper 12059, National Bureau of Economic Research 2006.

Rayo, Luis and Gary S. Becker, "Evolutionary Efficiency and Happiness," 2005. University of Chicago.

Siegfried, John J. and Wendy A Stock, "The Labor Market for New Ph.D. Economists," Journal of Economic Perspectives, 1999, 13, 115-34.

_ and _ _ "The Market for New Ph.D. Economists in 2002," American Economic Review, 2004, 94, $272-285$.

Siow, Aloysius, "Are First Impressions Important in Academia?," Journal of Human Resources, 1991, 26, 236-255.

Smeets, Valerie, "Are There Fast Tracks in Economic Departments? Evidence from a Sample of Top Economists," 2004. Aarhus School of Business. 
Swidler, Steve and Elizabeth Goldreyer, "The Value of a Finance Journal Publication," Journal of Finance, 1998, 53, 351-363.

Tervio, Marko, "Mediocrity in Talent Markets," 2005. University of California, Berkeley.

__ , "Network Analysis of Three Academic Labor Markets," 2005. University of California, Berkeley.

Waldman, Michael, "Job Assignments, Signaling, and Efficiency," RAND Journal of Economics, 1984, $15,255-267$.

Weinberg, Bruce A. and David W. Galenson, "Creative Careers: The Life Cycles of Nobel Laureates in Economics," 2005. Ohio State University and University of Chicago. 